\title{
O SOLFEJO NA ABORDAGEM PEDAGÓGICA DE EDGAR WILLEMS E AS PROPOSTAS DE SOLFÈGE-COURS ÉLÉMENTAIRE
}

\author{
The solfeggio in the musical pedagogy of \\ Edgar Willems and the proposals of Solfège- \\ cours élémentaire
}

\author{
El solfegio en el enfoque pedagógico de \\ Edgar Willems y las propuestas de Solfège- \\ cours élémentaire
}

\author{
NILCEIA PROTÁSIO \\ Universidade Federal de Goiás \\ nilceiaprotasio@gmail.com
}

\begin{abstract}
Resumo: O objetivo do presente texto consiste em abordar o solfejo na pedagogia musical de Edgar Willems, descrever alguns elementos de seu pensamento sobre o desenvolvimento auditivo e apontar aspectos relevantes em sua obra Solfège: cours élémentair. Como contexto, são apresentados aspectos referentes à canção, à consciência melódica e ao solfejo. Posteriormente, de modo detalhado, conteúdos do livro Solfège: cours élémentaire. O livro contém três grandes partes, destinadas à preparação para o solfejo, ao solfejo propriamente dito e a dados teóricos e práticos. Dos motivos e ordenações, Edgar Willems nos conduz aos solfejos com intervalos harmônicos, combinando segundas, sétimas, quartas e quintas, posteriormente, intervalos de oitavas e décimas. A leitura vertical alcança sua complexidade na leitura a três vozes e nos acordes de quatro sons. Conclui-se que Solfège: cours élémentaire propicia um aprendizado vivo, cujo centro é o desenvolvimento da musicalidade e da audição e a força expressiva da música.
\end{abstract}

Palavras-chave: Edgar Willems. Solfejo. Desenvolvimento auditivo.

\begin{abstract}
The present work consists of approaching the solfeggio in the musical pedagogy of Edgar Willems, to indicate some elements of his thought about auditory development and to highlight important aspects in his work Solfège: cours élémentair. As a context, aspects related to music are presented, along with melodic movement and solfeggio. Subsequently, in a detailed way, part of the content of the book Solfège: cours élémentaire is also approached. The book contains three longer parts, focusing on the preparation of the solfeggio, on the solfeggio itself, and on the theoretical and practical data. From the motives and ordinations, Edgar Willems leads us to solfeggio with harmonic intervals, combining the second, seventh, fourth and fifth, and then to the intervals of octaves and tenths. The vertical reading achieves its complexity in three-voice and four-chord readings. It is concluded that Solfège: cours élémentaire provides an active learning, from which the center is the development of musicality and hearing, and the expressive force of music.
\end{abstract}

Keywords: Edgar Willems. Solfeggio. Auditory development.

Resumen: El objetivo de este trabajo es abordar el solfeo en la pedagogía musical de Edgar Willems, describir algunos elementos de su pensamiento sobre el desarrollo auditivo y señalar aspectos relevantes en su trabajo Solfège: cours élémentair. Como contexto, se presentan aspectos relacionados con la canción, la conciencia melódica y el solfeo. Posteriormente, en detalle, los contenidos del libro Solfège: cours élémentaire. El libro contiene tres partes principales para la preparación de solfeo, solfeo apropiado y datos teóricos y prácticos. A partir de los motivos y las ordenanzas, Edgar Willems nos lleva a las solfeas con intervalos armónicos, combinando segundo, séptimo, cuarto y quinto, y luego intervalos de octava y décima. La lectura vertical alcanza su complejidad en la lectura de tres voces y los acordes de cuatro sonidos. Se concluye que Solfège: cours élémentaire proporciona un aprendizaje vivo, cuyo centro es el desarrollo de la musicalidad y la audición y la fuerza expresiva de la música.

Palabras clave: Edgar Willems. Solfege. Desarrollo auditivo. 


\section{INTRODUÇÃO}

As palavras de Edgar Willems em uma de suas canções de intervalos enriquecem de forma poética alguns de seus solfejos: "Todos os nossos risos e todas as nossas lágrimas fazem uma mistura doce em nossos corações"1. O canto, a melodia e a audição ocupam lugar de destaque em sua metodologia e abrem uma gama de possibilidades para o desenvolvimento auditivo - habilidade essencial na formação musical.

As ideias pedagógicas de Edgar Willems (1890-1978) marcaram a educação musical do século XX e reverberam na atualidade. Sua metodologia transcende a iniciação musical, perpassando o longo e abundante caminho do aprendizado, onde algumas lições fazem parte, como: uma sólida preparação auditiva e rítmica; o desenvolvimento da musicalidade e a aquisição de sentido de intervalos e tonalidades; atividades de entonação e de percepção auditiva, nas quais são valorizadas a leitura e a escrita musicais ${ }^{2}$.

A versão espanhola de L'oreille musicale é dedicada a Jaques-Dalcroze, que assina o prólogo da obra e é a quem Edgar Willems chama de "pioneiro da cultura auditiva". Portanto, em El oido musical: La preparación auditiva del niño (Willems, 2001), o autor discorre com profundidade sobre questões referentes à audição, ao desenvolvimento auditivo sensorial, afetivo e mental, à inteligência auditiva e à preparação auditiva. Parâmetros de altura, espaços intratonais, timbre e intensidade, assim como memória, audição interior e imaginação criadora compõem, conjuntamente, os pilares de sua pedagogia.

De início, indagamos: Como Edgar Willems compreende o campo dos elementos auditivos? Em sua perspectiva, quais os fatores que interferem na complexidade da audição, e de que ordem são as dificuldades na receptividade e na consciência do som? Embora não sejam questões centrais deste texto, configuram-se como pontes a nos conduzir ao patamar do solfejo.

Willems (2001) assegura que o ouvido pode desenvolver-se de forma a adquirir a noção do som e da audição, no entanto, podem surgir dificuldades no que se refere à receptividade sensorial, à sensibilidade afetiva e à inteligência auditiva. Para ele, a melodia nasce da afetividade própria das relações sonoras, sendo, portanto, diretamente dependente da nossa sensibilidade emocional (Chapuis; Westphal, 1980, p. 150). A sensorialidade não deve ser confundida com a consciência sensorial, sendo a receptividade sensorial ligada ao ouvir e a consciência sensorial ligada ao escutar: a primeira se refere ao aspecto passivo, e a segunda ao aspecto ativo do mesmo processo.

\footnotetext{
${ }^{1}$ Canção Tous nos rires, da obra Chansons d'intervalles (Willems, 1996, p. 2).

${ }^{2}$ Aspectos de iniciação à leitura e escrita musicais foram tratados em outro texto (PROTÁSIO, 2018).
} 
A sensibilidade afetivo-auditiva (tomada em um sentido não apenas musical, mas geral) começa no momento em que passamos do ato passivo e objetivo de ouvir ao de escutar, mais ativo e subjetivo. Escuta-se motivado por um desejo, por uma emoção (medo-surpresa). Um interesse está em jogo. Este interesse chama a atenção, o que se torna um ponto útil e até necessário para o surgimento da consciência sonora (Willems, 2001, p. 55, tradução nossa) ${ }^{3}$.

Por sua vez, inteligência auditiva não deve ser confundida com conhecimento no campo intelectual do som, mas "pode ser considerada como uma síntese abstrata das experiências sensoriais e afetivas, uma vez que trabalha com seus dados: normalmente o denominamos com a palavra 'entender" (Willems, 2001, p. 59, tradução nossa) ${ }^{4}$. Nessa vertente, direcionam-se outros elementos da inteligência musical, como: memória, audição interior, imaginação criativa, sentido tonal, audição relativa e absoluta, nome da nota e do acorde.

A memória e a audição interna comportam três tipos, incluindo os aspectos biológico, afetivo e mental. Especificamente sobre audição relativa, Willems defende que esta pertence ao dominio da sensibilidade afetiva: "Consiste na percepção de relações entre dois ou vários sons. Essas relações determinam em nós reações de satisfação (consonâncias) ou insatisfação (dissonâncias), ou reações emocionais de várias naturezas" (Willems, 2001, p. 60, tradução nossa) ${ }^{5}$. Por sua vez, concebe a audição absoluta como fenômeno de ordem fisiológica. É importante ressaltar que Willems defende tanto a audição absoluta quanto a audição relativa, sendo que a primeira oferece algumas vantagens práticas e baseia-se na memória sonora e nominal (sons e nomes), e a segunda está relacionada à sensibilidade afetiva e à inteligência ${ }^{6}$. Em sentido análogo, Willems (2011, p. 174) difere as leituras absoluta e relativa, admitindo-as como complementares, sendo que a primeira fixa a nota segundo a clave e é vantajosa para o dominio da leitura, e a segunda consiste na relação de uma nota com outra e é de natureza artística. Adverte, portanto, que não devemos confiar exclusivamente na leitura absoluta, como geralmente é feito.

\footnotetext{
3 "La sensibilidad afectivo-auditiva (tomada en un sentido no sólo musical, sino general) comienza en el momento en que pasamos del acto pasivo y objetivo de oír al de escuchar, más activo y subjetivo. Se escucha motivado por un deseo, por una emoción (miedo-sorpresa). Un interes está en juego. Este interés fija la atención, que se convierte así em un punto útil e incluso necesario para la eclosión de la conciencia sonora" (Willems, 2001, p. 55).

4 "[...] puede ser considerada como una síntesis abstracta de las experiencias sensoriales y afectivas puesto que trabaja sobre sus datos: la nombramos normalmente con la palabra 'comprender"' (Willems, 2001, p. 59).

5 "Consiste en la percepción de relaciones entre dos o varios sonidos. Estas relaciones determinan en nosotros reacciones de satisfacción (consonancias) o de insatisfacción (disonancias) o reacciones emotivas de diversas naturalezas" (Willems, 2001, p. 60).

${ }^{6}$ Embora não seja o foco deste texto discutir questões específicas sobre ouvido relativo e absoluto, é oportuno indicar Gainza (2010, p. 55-59).
} 
O objetivo do presente texto, portanto, consiste em abordar o solfejo na pedagogia musical do educador musical Edgar Willems, descrever alguns elementos de seu pensamento sobre o desenvolvimento auditivo e apontar aspectos relevantes em sua obra Solfège: cours élémentaire. A metodologia consistiu na análise dos solfejos e nas considerações feitas pelo próprio autor na publicação supracitada, buscando destacar exemplificar a introdução de elementos novos, a condução e o seguimento dos exercícios. Optamos por apresentar de modo mais detalhado os exercícios presentes nessa obra, tomando como base a versão "Livre du maitre" (Willems, 1988), por se constituir em um material pedagógico rico, didático e apropriado em diferentes contextos de educação musical. Convém mencionar a existência de uma versão portuguesa da obra, adaptada por Raquel Marques Simões (Willems, 1998) ${ }^{7}$.

Nas palavras de Violeta Hemsy de Gainza (2010, p. 20, tradução nossa), Edgar Willems "[...] é uma figura brilhante no campo pedagógico musical $[\ldots]$, as contribuições e ideias pedagógicas de Willems são hoje de grande relevância e longe de serem superadas" ${ }^{\prime}$. Foi um apóstolo da verdade, da bondade, da beleza na música. No entanto, ignorado por muitos educadores (Gainza, 1980, p. 111). Por sua vez, Carmem Maria Mettig Rocha (1990, p. 10) enaltece a pessoa do educador e seus princípios teóricometodológicos, admitindo-se "completamente maravilhada" depois de conhecê-los - passando a estudar o seu método de modo aprofundado.

A convicção de que Solfège: cours élémentaire pode contribuir significativamente para o desenvolvimento auditivo constitui a motivação central deste texto e, ao mesmo tempo, nos impulsiona a problematizar o ensino do solfejo no contexto da educação musical.

\section{AS CANÇÕES E A CONSCIÊNCIA MELÓDICA}

As canções desempenham função importante na metodologia de Edgar Willems, sobretudo na infância - sejam canções simples, sejam canções com intervalos, que, segundo ele, devem proporcionar alegria e provocar o desejo de fazer música. Enquanto umas favorecem o senso rítmico, outras preparam o ouvido musical, seja pelos intervalos ou pela harmonia que as acompanha. Há canções, por exemplo, em terça menor descendente ou de golpes dados em uma porta: "toc-toc-toc". Outras partem de um termo, como: "bom dia", "adeus", "sim-sim", "não-não" etc. Há ainda canções que trabalham o sentido plástico por meio de mímica, movimentos corporais e dança.

\footnotetext{
${ }^{7}$ Em 1964, Willems concedeu o diploma de Ensino e Didática em Educação Musical, Método Edgar Willems, a Jacques Chapuis e Raquel Simoes, em Lisboa. Este diploma dá o direito de treinar professores do método (Chapuis; Westphal, 1980, p. 36).

8 “[...] es una figura brillante dentro del campo pedagógico musical [...] los aportes y las ideas pedagógicas de Willems resultan hoy de gran actualidad y lejos de haber sido superados" (Gainza, 2010, p. 20).
} 
As canções de duas a cinco notas oferecem uma série de vantagens para o estudo do solfejo ou dos instrumentos, pois, por um lado, as cinco primeiras notas nos dão a relação de tônica-dominante e, por outro, a mão tem cinco dedos (Willems, 2011, p. 35, grifo do autor, tradução nossa) ${ }^{9}$.

Ao apresentar alguns aspectos ligados à vida e à obra de Edgar Willems e à sua proposta pedagógica, Parejo (2011) destaca o uso de canções populares tradicionais, canções simples elaboradas sobre palavras e ações cotidianas, canções que preparam para a prática instrumental, compostas sobre o pentacorde, canções com mímicas, canções ritmadas, canções improvisadas e canções de intervalos. Especificamente sobre as canções de intervalos, Willems orienta para que se comece com intervalos de segundas ou terças maiores e menores, seguidas de quartas e quintas justas:

[...] as crianças podem aprender o nome dos intervalos e cantar a partir de uma tônica: segunda a segunda, a terça, a quarta etc. Não é uma questão de teoria, mas um simples jogo ordenado, mostrando, eventualmente, o salto sobre os dedos separados de uma mão (Willems; Chapuis, 1993, p. 16 , tradução nossa) ${ }^{10}$.

A intenção é fazer nascer a consciência do valor expressivo dos intervalos e despertar a sensibilidade. Ao tratar dos intervalos sonoros, Willems (1984) enfatiza a aproximação, tão presente em sua pedagogia, entre a evolução artística e as leis da vida, partindo do inconsciente para o consciente. Neste caso, "[...] as canções constituem um excelente ponto de partida porque, cantando, a criança inconscientemente faz um ato musical sintético, onde ritmo, melodia e harmonia formam um todo" (Willems, 1984, p. 52 , tradução nossa) ${ }^{11}$.

Os nomes das notas e dos graus permitem tomar consciência dos elementos melódicos e harmônicos. A consciência mental, reflexiva e melódica será indispensável para a escrita e a leitura. Ele defende que o aluno aprenda as duas claves, de sol e de fá, ao mesmo tempo, e do mesmo modo deve aprender a ler não apenas horizontalmente, mas também verticalmente (Willems, 1994, p. 116) ${ }^{12}$. Para o exercício do solfejo, advoga a

\footnotetext{
9 "Las canciones de dos a cinco notas ofrecem una serie de ventajas para el estudio del solfeo o los instrumentos, ya que, por un lado, las cinco primeras notas nos dan la relación de tónica a dominante, y, por otro, la mano tiene cinco dedos" (Willems, 2011, p. 35, grifo do autor).

10 “[...] se puede enseñar a los niños el nombre de lós intervalos y hacerlos cantar a partir de una tónica: 'una segunda, una tercera, una cuarta,'etc. No es una cuestión de teoria, sino un simple juego ordenado, mostrando, eventualmente, el salto sobre los dedos separados de una mano" (Willems; Chapuis, 1993, p. 16).

${ }^{11}$ “[...] les chansons constituent un point de départ excellent car, en chantant, l'enfant fait inconsciemment un acte musical synthétique où rythme, mélodie et harmonie forment un tout" (Willems, 1984, p. 52).

${ }^{12} \mathrm{Na}$ perspectiva willemsiana, a iniciação das crianças deve se dar de forma menos consciente possível, com imitações e descobertas. No segundo ano se desenvolve a consciência auditiva e rítmica. Durante o terceiro ano, que Willems denomina de pré-solfejo, há a consciência da ordem dos sons, ordem dos nomes e ordem
} 
importância de uma preparação com prática de canções, exercícios auditivos, exercícios rítmicos e exercícios com os nomes das notas.

\section{O SOLFEJO NA ABORDAGEM DE EDGAR WILLEMS}

É fato que o solfejo é considerado uma atividade laboriosa e desafiadora para muitos estudantes de música. Algumas pesquisas realizadas e experiências compartilhadas discorrem sobre os diversos aspectos que envolvem o solfejo, seu ensino e sua aprendizagem (Freire, 2005a, 2005b, 2008; Santos; Gerling; Hentschke, 2005). Não desprezando tais abordagens que, inclusive, contribuem para uma visão crítica e atualizada da prática do solfejo, mas justificados por questões de delimitação, este texto avança no sentido de contextualizar o solfejo na abordagem de Edgar Willems.

Novamente trazemos à tona os domínios contidos em suas ideias sobre o desenvolvimento auditivo: a sensorialidade, caracterizada pela atividade do órgão auditivo como tal, em sua reação ao som; a sensibilidade afetiva e emotiva, que é a chave da experiência dos intervalos e da melodia; e a inteligência auditiva, que diz respeito ao conhecimento intelectual dos fenômenos sonoros. Para Willems (1966, p. 14-15), esses três dominios se misturam, portanto, é necessário que o educador perceba a proporção em que são apresentados - o que dependerá do aluno ou do grupo. O professor lida com aptidões musicais diversas - o que pode se constituir em uma dificuldade:

A diversidade de habilidades é, portanto, uma primeira dificuldade que se soma à diversidade de inteligências. Uma segunda dificuldade decorre do fato de que se impõe com frequência aos professores um programa de solfejo que excede as possibilidades da maioria das crianças. $O$ problema do solfejo é muitas vezes mal apresentado. Geralmente, se peca por excesso de intelectualismo. O estabelecimento de bases rítmicas (instinto dinâmico e sentido agógico) e auditivo (especialmente a audição sensorial) foi negligenciado. [...] Uma terceira dificuldade, e não das menores, vem do fato de que muitos professores de música ignoram a natureza $e$ as vantagens de uma preparação musical que pode preceder a escrita e a leitura (Willems, 1966, p. 37, grifo do autor, tradução nossa) ${ }^{13}$.

das notas escritas sobre o pentagrama, inicialmente, de cinco linhas sem clave e, posteriormente, pentagrama de onze linhas, com duas claves (Willems, 1994, p. 112).

13 "La diversidad de aptitudes es pues una primera dificultad que se suma a la diversidad de las inteligencias. Una segunda dificuldad proviene del hecho de imponerse con frecuencia a los profesores un programa de solfeo que excede las posibilidades de la mayoria de los ñinos. El problema del solfeo está a menudo mal planteado. Se peca por lo general de um exceso de intelectualismo. El establecimiento de las bases rítmicas (instinto dinámico y sentido agógico) y auditivas (especialmente la audición sensorial) há sido descuidado. [...] 
Nessa perspectiva, o solfejo não deve estar descolado da prática instrumental e nem se encontrar separado das demais disciplinas. Pelo contrário, deve ocupar seu lugar, constituindo apoio para o estudo do instrumento, da harmonia, da improvisação e da composição. Jacques Chapuis (1995, p. 2), que dedicou parte da sua vida à divulgação e ao desenvolvimento do legado deixado por Edgar Willems, articula esses fatores e afirma que, por meio de uma improvisação cada vez mais estruturada, a fantasia sempre encontra o seu lugar - tece esta consideração fazendo referências à improvisação musical, que precede e nutre a improvisação instrumental.

Nas palavras do próprio mestre:

O solfejo deve ser sempre vivo, baseado no instinto rítmico, na audição relativa e na participação ativa dos alunos. Por isso é indispensável fazer, como em todas os graus da aprendizagem musical, o mínimo de improvisação. Essa deve ser rítmica e melódica, primeiro sem o nome das notas, e depois com os nomes, com a ajuda, de vez em quando, de uma cadência harmônica interpretada ao piano pelo professor (Willems, 2011, p. 184-185, tradução nossa) ${ }^{14}$.

Posto um destaque particular para a improvisação, é possivel vislumbrar as abundantes possibilidades de proporcionar experiências nas quais os alunos podem criar e combinar os sons e os ritmos, alicerçando determinados conteúdos. O professor, por sua vez, estimula, participa e ampara as iniciativas e ações dos estudantes.

Ao focar a etapa de iniciação musical, a escala maior será a base. E, nesse sentido, deve ser considerada como um conjunto de intervalos a partir da tônica, e não uma sequência de tons e semitons. Willems acredita que iniciar pela escala de Dó favorece a associação entre o som e o nome, o que ele denomina de audição absoluta, útil para a prática musical (Willems, 2011, p. 158).

A escala será objeto de todo o nosso cuidado. A ordem fundamental que adotamos é a de sete sons diatônicos em graus conjuntos. A esta ordem de sons será acrescentada

Una tercera dificultad, y no de las menores, proviene de que muchos profesores de música ignoran la natureza y las ventajas de una preparación musical que puede preceder a la escritura y a la lectura" (Willems, 1966, p. 37 , grifo do autor).

\footnotetext{
14 “El solfeo debe ser siempre vivo, basado en el instinto rítmico, la audición relativa y la participación activa de los alumnos. Por eso es indispensable hacer, como en todos los grados del aprendizaje musical, un mínimo de improvisación. Ésta debe ser rítmica y melódica, primero sin el nombre de las notas, y luego con los nombres, con la ayuda, de vez en cuando, de una cadencia armónica interpretada al piano por el profesor" (Willems, 2011, p. 184-185).
} 
uma ordem de sete nomes em graus conjuntos, bem como uma escrita de notas em graus conjuntos. A maioria das dificuldades encontradas em alguns métodos na abordagem do solfejo vem do fato de que não se respeita a ordem por graus conjuntos (Willems, 1994, p. 208, grifo do autor, tradução nossa) ${ }^{15}$.

O autor enaltece a importância do sentido tonal. Todas as escalas estão baseadas na mesma melodia diatônica, com sete nome de notas. São excluídos os vocábulos utilizados para caracterizar alterações que, segundo Willems, agravam o problema auditivo em vez de facilitar (Willems, 1966, p. 16). O desenvolvimento auditivo começa com a audição melódica de canções, depois a escala, os intervalos, e os acordes simples, maiores e menores (Ibid., p. 119-120).

Willems (1994, p. 121) reconhece o descuido para a leitura a duas vozes no ensino musical, que, muitas vezes, passa do solfejo a uma voz à harmonia - começando pelo encadeamento dos acordes de três sons. Interessa, portanto, destacar a importância do trabalho a duas vozes e mostrar como este pode ser realizado. O objetivo é auxiliar a audição da simultaneidade dos sons.

Sobre a inserção e integração curricular, ele recomenda que as lições de solfejo aconteçam pelo menos uma vez por semana, sendo: vinte minutos de canto com intenções pedagógicas; quinze minutos de exercícios de audição e de ritmo, sempre com alguma improvisação; dez minutos de leitura e quinze minutos de ditado. Neste, alguns procedimentos são utilizados: 1) O professor toca o trecho inteiro para que os alunos determinem o compasso e a tonalidade (a nota lá será dada ao início e ao final); 2) Devem ser percebidos os tempos e a subdivisão dos mesmos, e, a partir da nota lá, determinada a tônica; 3) O professor corrige para que não se prossiga com equívocos; 4) Por trechos menores, os alunos memorizam por meio de repetições; 5) Os alunos repetem, entoando, e depois com o nome das notas; 6) Por fim, as frases são escritas - parte melódica e depois parte ritmica.

Os xilofones e os metalofones têm muitas vantagens para o estudo do solfejo. Bem afinados, eles podem ser usados coletivamente. Instrumentos de percussão podem ser recomendados, especialmente os de boa qualidade. Embora não defenda a dependência do instrumento no estudo do solfejo, Willems (1988, p. 22) reconhece as vantagens dos instrumentos ao estabelecer a consciência das ordenações dos sons e dos nomes.

\footnotetext{
15 “La escala será objeto de todos nuestros cuidados. El orden fundamental que adoptamos es el de siete sonidos diatónicos por grados conjuntos. A este orden de sonidos se agregará un orden de siete nombres por grados conjuntos al igual que una escritura de notas por grados conjuntos. La mayoría de las dificultades que encuentran algunos métodos para la aproximación al solfeo proviene del hecho de que no se respeta el orden por grados conjuntos" (Willems, 1994, p. 208, grifo do autor).
} 


\section{AS PROPOSTAS DE SOLFĖGE-COURS ÉLÉMENTAIRE}

Segundo Parejo (2011, p. 98), a obra Solfège élémentaire tem sido adotada em muitas instituições no Brasil. No entanto, "a utilização consciente do livro pressupõe a vivência de práticas auditivas refinadas propostas ao longo dos três primeiros graus ${ }^{16}$, além do treinamento dos automatismos de leitura que caracterizam o quarto grau". Nesse sentido, a autora destaca o trabalho realizado por Maria Mettig Rocha, no Brasil, cuja base e especificidade estão em pleno acordo com os princípios pedagógicos da metodologia willemsiana (PAREJO, 2011, p. 98).

O livro Solfège: cours élémentaire contém três grandes partes divididas em capítulos, destinadas à preparação para o solfejo, ao solfejo propriamente dito e a dados teóricos e práticos, dentre eles: transposição, improvisação e ditado (Willems, 1988). De início, o autor esclarece:

O solfejo diz respeito, antes de tudo, à leitura e escrita musicais. Sob este duplo aspecto, é, portanto, de natureza intelectual. No entanto, como se destina a servir à arte musical, é indispensável que ele tenha bases rítmicas e auditivas vivas, caso contrário, arrisca manter os alunos longe da música. A dificuldade será viver primeiro os elementos essenciais e depois levar os alunos à consciência reflexiva (Willems, 1988, p. 17, grifo do autor, tradução nossa $)^{17}$.

As afirmações de Jaques Chapuis, no prefácio da $3^{\mathrm{a}}$ edição, reafirmam a grandeza da obra: "Este livro, fruto de cinquenta anos de experiência prática, de estudo e de reflexão sobre as artes e a música, situa-se no centro de um universo pedagógico e psicológico muito vasto, no qual o passado canta no presente, e, este, no futuro" (Willems, 1988, p. 11, tradução nossa) $)^{18}$. Segue enaltecendo:

Edgar Willems leu muito, comparou e pressentiu. [...] Lembremo-nos apenas que, em sua opinião, era essencial que os princípios do início permanecessem válidos até o final dos estudos. Ele foi, portanto, fiel a si mesmo dessa maneira. Mas esta também é a razão para o tempo que ele levou para

\footnotetext{
${ }^{16}$ Embora os graus pedagógicos sejam flexíveis e adaptáveis, a sugestão consiste em: 10 Grau - Iniciação Musical (de 3 a 4 anos); 2o Grau - Iniciação Musical (de 4 a 5 anos); 3o Grau - Pré-Solfégico e Pré-Instrumental; 4으 Grau - Solfejo vivo (de 6 a 7 anos) (Ibid.). Programa e conteúdos mais detalhados para os diferentes graus pedagógicos podem ser encontrados em Chapuis (1990).

17 "Le solfège concerne, avant tout, la lecture et l'écriture musicales. Sous ce double aspect il est donc de nature intellectuelle. Mais, comme il est destiné à servir l'art musical, il est indispensable qu'il ait des bases rythmiques et auditives vivantes, sans quoi, il risque d'éloigner les élèves de la musique. La difficulté consistera à faire vivre d'abord les éléments essentiels et amener les eleves ensuite à la conscience réfléchie" (Willems, 1988, p. 17, grifo do autor).

18 “Ce livre, fruit de cinquante annéss d'expérience pratique, d'étude et de réflexion sur les arts et la musique, se place au centre d'un univers pédagogique et psychologique três vaste, dans lequel le passe chante dans le présent, et, celui-ci, dans l'avenir" (Willems, 1988, p. 11).
} 
realizar seu Curso Elementar de Solfejo (Willems, 1988, p. 12 , tradução nossa) ${ }^{19}$.

Antes de apresentar alguns exemplos de como Edgar Willems propõe a iniciação ao estudo do solfejo, é oportuno mencionar sua proposta de ordenações, que pode ser definida como a progressão de um motivo melódico realizado na tônica e repetido em todos os graus da escala. A intenção é ajudar a adquirir e a firmar o automatismo dos nomes das notas e, por meio deles, favorecer a tomada de consciência de determinados elementos musicais (Willems, 1998, p. 137). Nesse caso, o motivo-tema é repetido em todos os graus da escala, no sentido ascendente e descendente, como demonstrado na Figura 1. Além de entoar e cantar com as notas de diferentes tonalidades, pode-se escrever.

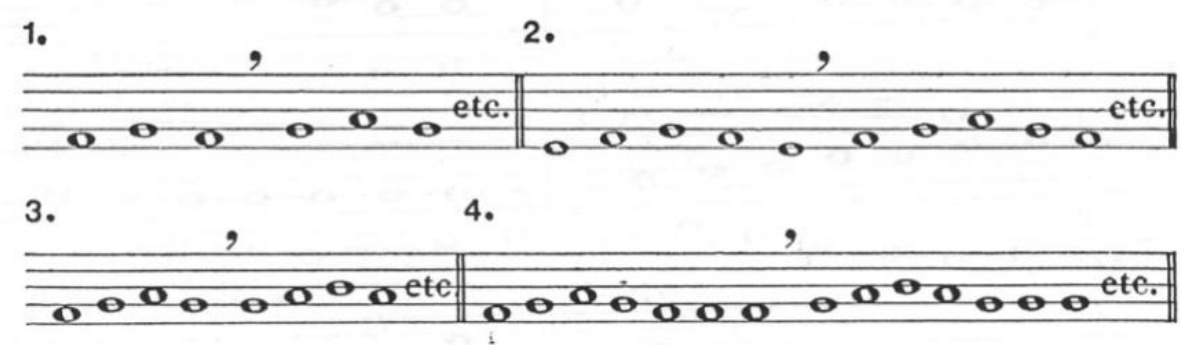

Figura 1: Motivos e ordenações (Willems, 1988, p. 38).

É possivel perceber que a iniciação à leitura na pedagogia Willems é baseada na relatividade, que envolve, além do aspecto auditivo movimentos de subida e descida -, o aspecto visual-cerebral, baseado nas relações entre as notas. Nesse sentido, o intervalo de terça é importante e estratégico, pois as notas são posicionadas na pauta sendo localizadas linha-linha ou espaço-espaço e inseridas no campo dos acordes de forma sobreposta, facilitando a compreensão dos mesmos, visual e intelectualmente.

A audição e a leitura por relatividade se articulam com a leitura absoluta. A leitura se inicia com um pentagrama simples sem clave para depois chegar à "pauta de onze linhas", com dois pentagramas, incluindo uma linha central de pontos. Segundo Willems (2011, p. 184), essa pauta tem incontestáveis vantagens. Para o início do solfejo, ele sugere um "flanelógrafo", que inclui os pentagramas, as claves e notas adesivas. Na Figura 2, um exemplo de solfejo nas duas claves, ainda sem indicação de compasso.

\footnotetext{
19 “Edgar Willems a beaucoup lu, compare et pressenti. [...] Rappelons seulement qu'à son avis, il était indispensable que les principes des débuts restent valables jusqu'à la fin des études. II a donc été fidèle à luimême dans cette voie. Mais, c'est aussi ce qui explique le temps qu'il a mis-pous réaliser son Cours Elémentaire de Solfège" (Willems, 1988, p. 12).
} 


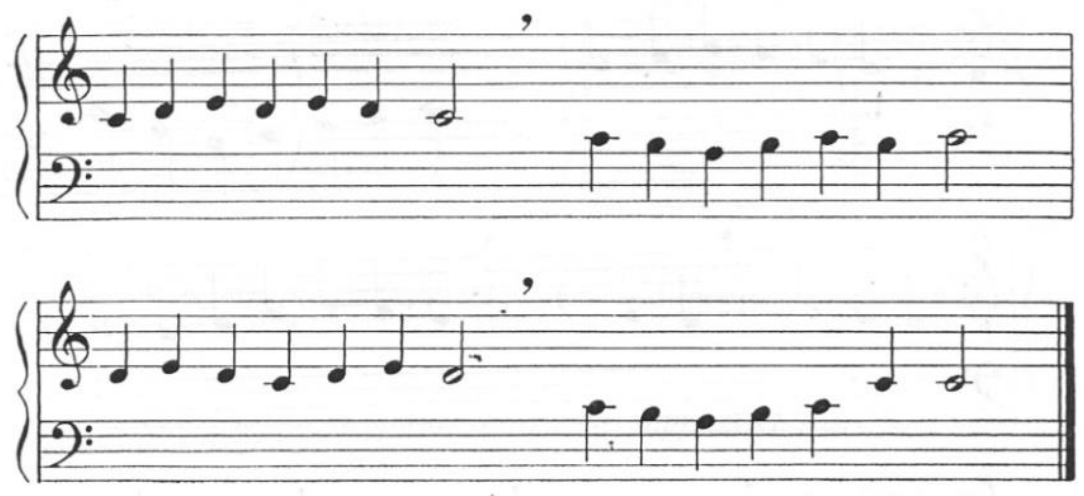

Figura 2: Aplicação em tricorde (Willems, 1988, p. 61).

Willems $(1988$, p. 65) considera o pentacorde Dó-Sol como um elemento global, sendo importante por seus dois polos: tônica e dominante. De igual modo, ele considera extremamente úteis as canções de duas a cinco notas, que deverão ser cantadas de memória com os nomes das notas. "As leituras de solfejos podem, ocasionalmente, ser enfatizadas por acordes, por beleza e também para ajudar o aluno. Mas aqui há um perigo, porque os estudantes devem ser capazes de assumir a responsabilidade pela entonação" (Willems, 1988 , p. 169) ${ }^{20}$. Nesse aspecto, vale ressaltar que a afinação é um ponto importante no trabalho de iniciação musical. Willems lembra que ela reside "na sensibilidade afetiva, e não na perfeição vocal, como muitos pensam; a afinação está diretamente ligada à faculdade de ouvir, de escutar e sentir a justeza dos sons" (Rocha, 1990, p. 28).

$\mathrm{O}$ autor sugere que tanto as notas altas como as notas graves sejam cantadas com leveza - a exemplo das Figuras 3 e 4. Justifica, segundo sua experiência, que a criança pode cantar sons altos e baixos ao pensar sobre esses sons - isso sem desconsiderar os limites vocais (Willems, 1988, p. 170).

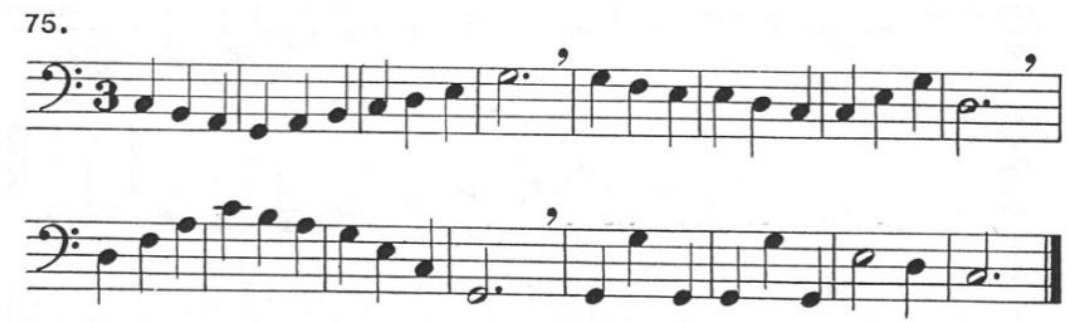

Figura 3: O grave na clave de fá (Willems, 1988, p. 84).

\footnotetext{
20 “Les lectures des solfèges peuvent, à l'occasion, être soulignées par des accords, pour la beauté, et aussi pour aider l'èlève. Mais là rédise un danger, car les èlèves doivent pouvoir prendre la responsabilité de l'intonation" (Willems, 1988, p. 169).
} 


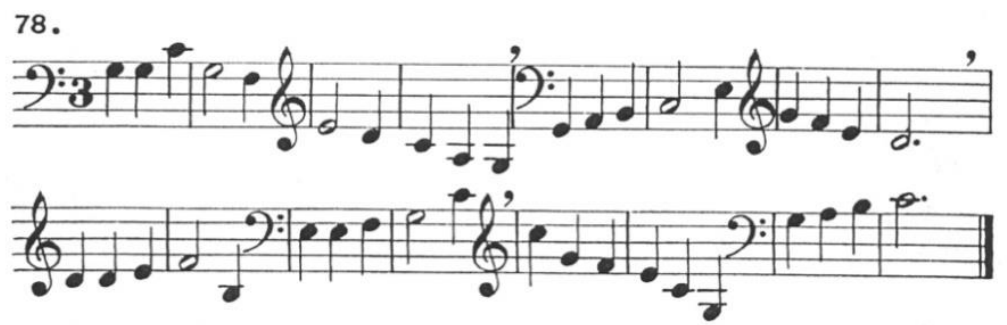

Figura 4: O alcance duplo (Willems, 1988, p. 85).

No contexto do solfejo, são valorizados os cânones, cujas leituras são precedidas por canções em cânones com palavras - o que, para Willems, facilita a execução. Estes podem ser muito mais rítmicos do que os cânones lidos e podem ser executados muito rapidamente, o que aumenta o interesse. O simples cânone a duas vozes consiste, na realidade, no canto por imitação, podendo ser vocalizado ou solfejado (Willems, 1988, p. 171172), como pode ser visto na Figura 5.

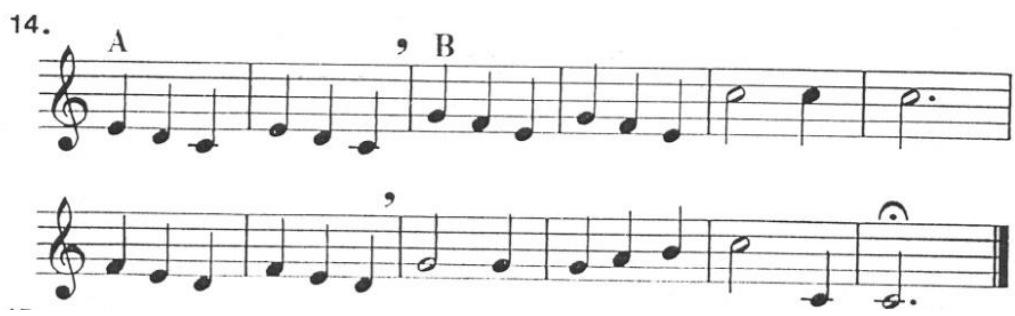

Figura 5: Cânone a duas vozes (Willems, 1988, p. 95).

Após a etapa dos cânones, permanece a ênfase na leitura a duas vozes, desta vez, com terças e sextas (Figura 6). A preocupação com o sentido tonal tem preponderância sobre o conhecimento das alterações, que, mesmo sendo importantes, são secundárias nesse momento. Além da tonalidade de Dó maior, são adicionadas Sol Maior, Ré Maior e Fá Maior (Willems, 1988, p. 172).

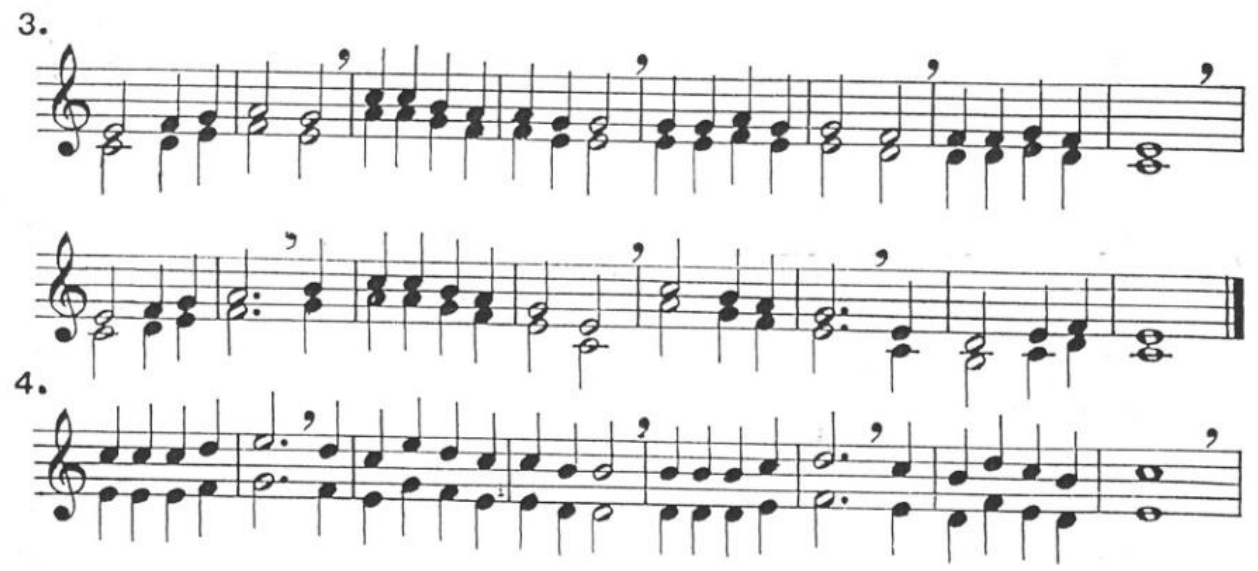

Figura 6: Leitura a duas vozes - Polifônico (Willems, 1988, p. 96). 
Os desdobramentos se dão no sentido de trabalhar notas longas em uma das vozes ou inserindo pausas, evitando, assim, o movimento paralelo em todo o tempo. Os ritmos prosseguem com simplicidade, se restringindo, basicamente, à semínima, à mínima e à semibreve, com suas respectivas pausas.

Mais adiante, a colcheia é incluída nas linhas melódicas do solfejo (Figura 7). Para Willems, o compasso de três colcheias é uma excelente introdução ao compasso de seis colcheias - ou seja, ao compasso composto (Willems, 1988, p. 173).

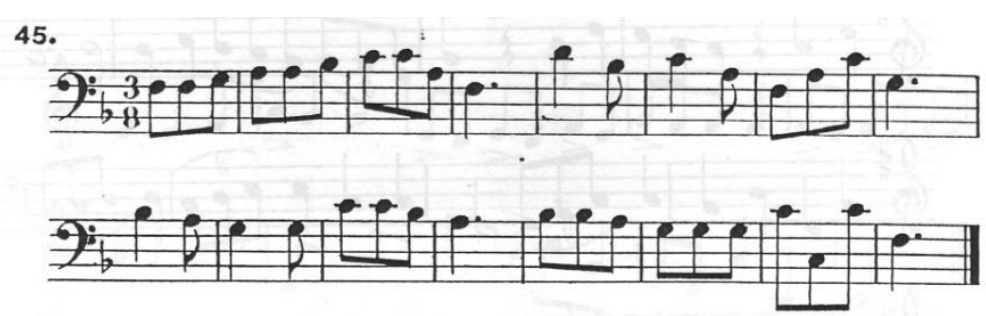

Figura 7: Leitura com três colcheias (Willems, 1988, p. 124).

Em algum momento, com o avançar dos exercícios, Willems ressalta que o conhecimento dos intervalos pode permanecer, no início, muito relativo: "O que importa aqui é o sentido tonal e o lugar de cada nota no tom. Estaremos satisfeitos com a consciência quantitativa (número de graus)" (Willems, 1988, p. 173, tradução nossa) ${ }^{21}$. Na Figura 8 nota-se a ênfase no intervalo de segunda:

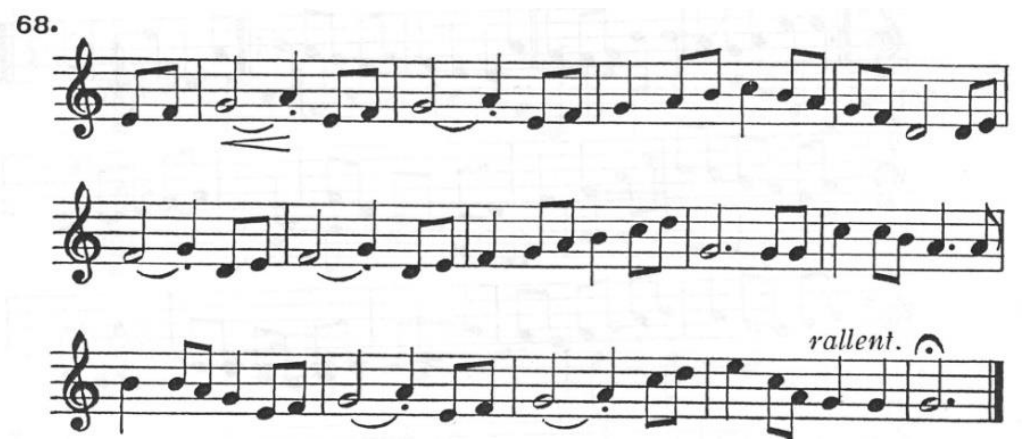

Figura 8: Capitulo VI - Estudo Consciente dos Intervalos (Willems, 1988, p. 132).

Conforme pode ser percebido no exemplo anterior, conjuntamente - e não descolado da melodia entoada - se fazem notórias as ligaduras, os sinais de respiração e os termos relacionados ao caráter musical ou à agógica. Na evolução dos exercícios, é possivel perceber, além desses fatores, a inserção de modulações (Figura 9):

\footnotetext{
21 “Ce qui importe, ici, c'est le sens tonal et la place de chaque note dans la tonalité. On se contentera de la conscience quantitative (nombre de degrés)" (Willems, 1988, p. 173).
} 


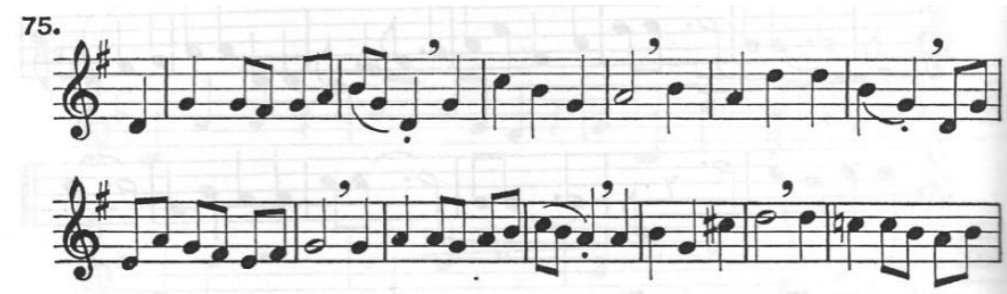

Figura 9: Estudo consciente dos intervalos - Quartas (Willems, 1988, p. 135).

Observa-se a riqueza da experiência musical por meio do solfejo, que não apenas treina a audição e desenvolve a entonação, mas reforça os conhecimentos teóricos, atribuindo sentido à ação de cantar. Os solfejos constituem um exercício de interpretação onde o aprendiz demonstra sua compreensão da ideia musical e executa expressivamente o que está proposto. Cantar com energia e executar com o sinal de repetição são indicações inseridas no solfejo a seguir, que, além de trabalhar grandes intervalos, inclui modulação (Figura 11):

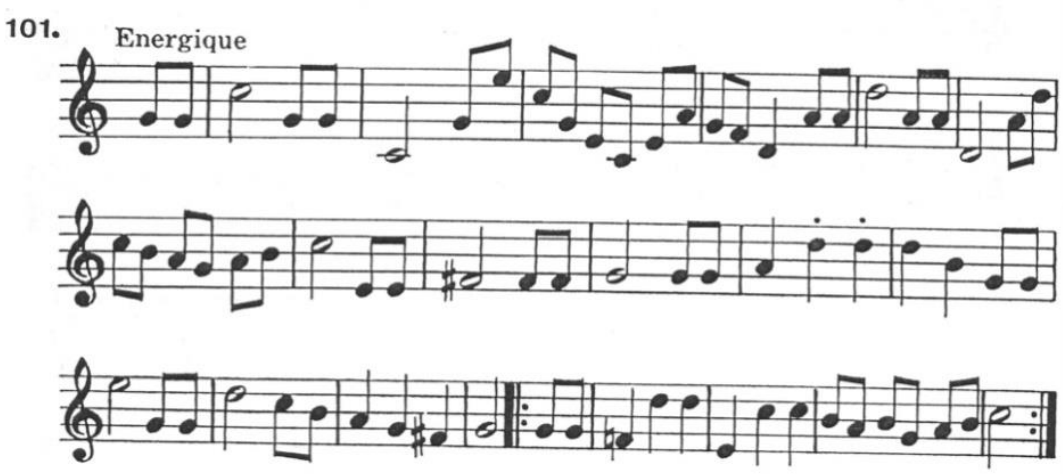

Figura 11: Solfejos com grandes intervalos (Willems, 1988, p. 141).

Por fim, Edgar Willems reforça a importância dos intervalos harmônicos, ou, conforme ele mesmo denomina, a leitura vertical. Iniciando com intervalos harmônicos em terças, segue para terças e sextas, e, posteriormente, quartas e quintas. Prossegue com os exercícios, combinando intervalos de segundas, sétimas, quartas e quintas no mesmo solfejo. Por fim, inclui intervalos de oitavas e décimas. A leitura vertical alcança sua complexidade na leitura a três vozes (conforme exemplo da Figura 12) e nos acordes de quatro sons. 


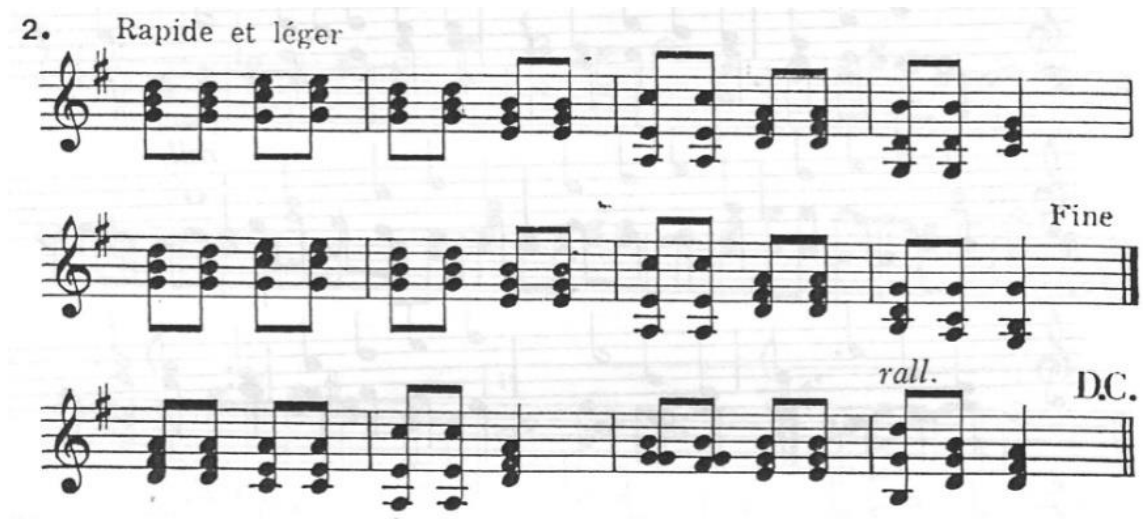

Figura 12: Leitura a três vozes (Willems, 1988, p. 148).

Segundo ele, os padrões dos intervalos harmônicos podem ser usados para leitura vertical, mas a percepção quantitativa de intervalos será adicionada. "As qualificações de intervalos menores e maiores não são levadas em conta; por outro lado, a natureza consonante e dissonante dos intervalos será levada em consideração (Willems, 1988, p. 173, grifo do autor, tradução nossa) ${ }^{22}$.

Willems nos adverte para dois pontos fundamentais nas lições iniciais de solfejo que serão úteis para a compreensão de toda sua pedagogia: 1) A promoção de um clima de vida, sem perder de vista a prática artísticomusical - sendo assim, algum tempo deverá ser reservado para a educação rítmica e auditiva; 2) Uma atitude criativa do professor, que deve buscar a participação e o envolvimento dos alunos: "O que nem sempre é fácil em classes numerosas [...]. Uma dose minima de improvisação, de criação (ainda que imitativa) é sempre possível" (Willems, 1966, p. 48, tradução nossa) ${ }^{23}$. No âmago dessa visão, manifesta-se uma educação musical dinâmica, sensorial, afetiva e mental, estando todos esses aspectos apoiados e vivificados por um objetivo de ideal humano: a educação musical em prol da educação humana.

\section{CONSIDERAÇÕES FINAIS}

Aproximando-nos da conclusão, evocamos questões levantadas por Violeta Hemsy de Gainza (2010, p. 51), que advertem o professor a recriar o método que aplica. Por sua vez, as indagações que este deve fazer devem contemplar a apropriação e a adequação, levando em conta as necessidades e as condições psicológicas naturais da criança. Embora as palavras da autora se refiram ao universo infantil, se tomarmos alguns elementos do processo de iniciação como sendo válidos para qualquer faixa etária, a afirmação ainda se aplica. A mesma autora reafirma que o método Willems

\footnotetext{
22 “Les qualifications d'intervalles mineurs et majeurs n'entrent pas en ligne de compte; par contre la nature consonante et dissonante des intervalles sera prise en considération" (Willems, 1988, p. 173, grifo do autor).

23 “Cosa que no siempre es fácil en las clases numerosas [...]. Una mínima dosis de improvisación, de creación (aunque fuese imitativa) es siempre posible" (Willems, 1966, p. 48).
} 
se preocupa com a formação auditiva nesse quesito, a "sensibilização e o treinamento sensorial se realizam com profundidade e afetam todos os níveis do ensino - inclusive o nivel superior" (Gainza, 2010, p. 38).

As diferentes vertentes da pedagogia willemsiana convergem, portanto, para a sensorialidade, a afetividade e a inteligência presentes no desenvolvimento auditivo. O conteúdo descrito e os trechos demonstrados retirados de sua obra Solfège: cours élémentaire demonstram a forma didática que tanto caracteriza a proposta pedagógica de Willems.

Mesmo que as questões centrais deste texto nos remetam a uma abrangência dificil de tratar, se considerarmos as ideias do educador musical Edgar Willems no campo dos elementos auditivos e na complexidade da audição, é possivel constatar coerência, conexão e unidade em sua proposta para o ensino do solfejo. Dos motivos e ordenações à leitura a três vozes, verificamos a pujança didática e as inúmeras possibilidades para o aprendizado do sentido de intervalos e tonalidades e para valiosas experiências de entonação e leitura musicais.

Além de constituir um material pedagógico rico, didático e apropriado em diferentes contextos de educação musical, Solfège: cours élémentaire propicia um aprendizado vivo, cujo centro é o desenvolvimento da musicalidade e da audição, e a força expressiva da música. Ouvir, escutar e entender ainda constituem grandes desafios da percepção musical, sobre os quais Edgar Willems tem muito a nos ensinar.

\section{REFERENCIAS}

CHAPUIS, Jacques. Panorama pedagógico da educação musical Willems: da iniciação musical ao solfejo vivo. Tradução M. C. de Brito. Revista Musica y Educacion, v. III, p. 13-32, 1990.

. Elementos de solfeo y armonia del linguaje musical. Fribourg:

Editions Pro Musica, 1995.

CHAPUIS, Jacques; WESTPHAL, Béatrice. Sur les pas d'Edgar Willems: une vie, une oeuvre, um idéal. Fribourg: Editions Pro Musica, 1980.

FREIRE, Ricardo Dourado. Características e focos de aprendizagem de diversos sistemas de solfejo. In: CONGRESSO DA ANPPOM, 15., 2005, Rio de Janeiro. Anais [...]. Rio de Janeiro: ANPPOM, 2005a. p. 385-392.

Sistemas de solfejo analisados a partir de conceitos de Robert Gagné. In: ENCONTRO INTERNACIONAL DE COGNIÇÃO MUSICAL, 1., 2005, Curitiba. Anais [...]. Curitiba: UFPR, 2005b.

. Sistema de solfejo fixo-ampliado: uma nota para cada sílaba e uma sílaba para cada nota. Opus, Goiânia, v. 14, n. 1, p. 113-126, jun. 2008. 
GAINZA, Violeta Hemsy de. Fundamentos, materiales y tecnicas de la educacion musical. Buenos Aires: Melos, 2010.

PAREJO, Enny. Edgar Willems: um pioneiro da educação musical. In: MATEIRO, Teresa; ILARI, Beatriz (Orgs.). Pedagogias em Educação Musical. Curitiba: Ibpex, 2011. p. 89-123.

PROTÁSIO, Nilceia. A introdução da leitura e da escrita na pedagogia musical de Edgar Willems. In: PALHARES, Taís Helena; PRADA, Teresinha. Música, estudos culturais e educação: trajetórias e perspectivas na pesquisa. Curitiba: Editora CRV, 2018. p. 73-83.

ROCHA, Carmem Maria Mettig. Educação Musical: Método Willems. Salvador: Faculdade de Educação da Bahia,1990.

SANTOS, Regina Antunes Teixeira dos Santos; GERLING, Cristina C.; HENTSCHKE, Liane. A aula de solfejo e as estratégias de resolução de problemas na proposta de Davidson e Scripp. In: CONGRESSO DA ANPPOM, 15., 2005, Rio de Janeiro. Anais [...]. Rio de Janeiro: ANPPOM, 2005. p. 370-377.

WILLEMS, Edgar. Educacion Musical: Guia Didáctica para el Maestro. Buenos Aires: Ricordi Americana, 1966.

. L'oreille musicale. Tome II. La culture auditive les intervalles et les accords. 5. ed. Fribourg-Suisse: Éditions "Pro Musica", 1984.

Solfège: cours élémentaire. Livre du maitre. 3. ed. Fribourg: Éditions "Pro Musica". 1988.

. El valor humano de la educación musical. Barcelona: Paidós, 1994.

Chansons d'intervalle - avec accompagnement de piano. 6. ed.

Fribourg: Éditions "Pro Musica”, 1996.

Solfejo: curso elementar. Adaptação portuguesa: Raquel Marques Simões. São Paulo: Fermata do Brasil, 1998.

2001.

El oído musical: la preparación auditiva del niño. Barcelona: Paidós,

Las bases psicológicas de la educación musical. Barcelona: Paidós, 2011.

WILLEMS, Edgar; CHAPUIS, Jacques. Los exercicios de la audición. Revista Musica y Educacion, ano VI, n. 16, p. 1-16, dez. 1993. 
Nilceia Protásio é Doutora em Educação e mestra em Educação pela Universidade Federal de Mato Grosso do Sul. Bacharela em Música, instrumento Piano, pela Universidade Federal de Goiás. Professora associada da Escola de Música e Artes Cênicas da Universidade Federal de Goiás (EMAC/UFG), atua especialmente nas áreas de práticas de ensino de música e metodologia da pesquisa. Desenvolve pesquisas na área de educação musical, contemplando temáticas ligadas à formação de professores, metodologia do ensino de música e música no contexto escolar. Integra comitês científicos de diversos eventos e atua como parecerista em revistas da área de música. Foi coordenadora da área de Música do Programa Institucional de Bolsa de Iniciação à Docência (Pibid) da Universidade Federal de Goiás. É coordenadora da Comissão de Pesquisa da EMAC/UFG e representante estadual de Goiás da Associação Brasileira de Educação Musical (Abem). https://orcid.org/0000-00033218-971X 